\title{
ALEXANDRU ARBUNESCU
}

Bijuterille elenistice, nu mal puțin decât alte forme de exprimare artistică ale grecilor dın ultımele veacurı înainte de Cristos, Invocă in mod constant aproplata legătură dintre om și forțele supranaturale. care se întrepătrundeau cu viața sa. Abundã reprezentărı de zel și zelțe, ca șı ale creaturilor mitologice varlate. Adeseorı divinitățlle nu erau reprezentate ele însele, cl simbolizate de unul dintre atributele zeltăților respectıve'. Estè și cazul unel interesante plese din "Colecția Orghıdan", care este expuså în Tezaurul Istoric de la Muzeul Național de Istorie a Româniel - un pandantiv din aur ${ }^{2}$, în formă de porumbel cu aripłle strânse - ce sugerează asocierea cu Afrodita. pe care grecll o reprezentau purtată în cerur de un car tras de porumbe1 $1^{3}$. Pe pleptul păsănil se încrucișează în chip de hamuri patru trese din filigran, ce converg către o casetã mică, rotundă. cu peretele din bandă din aur în "dințı de lup", care încastrează un "cabochon" din platră roșle. Terminațille cordıforme ale curelușelor au fost umplute Inț̣ial cu o pastă maro; care, astăzı se păstrează în numal una dintre cele patru inımioare. Ariplle, din foale din aur, se suprapun peste coada cvadrilobată și sunt mărginite de un fir sımplu. Penele sunt conturate în fillgran. Un anou din sârmă subțire, în forma literei "omega", este prins între anipl șl coadă. Porumbelul este montat pe un soclu cubic, cu colturile rotunjıte, din foale din aur, mărginit sus și jos de câte o tresã. Tresa superioară este dublată de un registru de ove, conturate în filigran, într-una dintre ele păstrându-se încă pasta maro, care, inț̣ial le umplea pe flecare. Plesa prezintă fisuri, urme de lovire și este ușor deformată. Pandantivul are înălțimea de 21, 1 mm., lungı̀mea de 24, $2 \mathrm{~mm}$., lățimea de $9.6 \mathrm{~mm}$. și greutatea de 2,67. gr.

Corpul porumbelului a fost obținut prin sudarea a două jumătăți identice din foale din aur, modelate prin clocănıre pe un model din platră sau din lemn. Ariplle și coada au fost lucrate separat, tot dın foale din aur și sudate de corp.

Filigranul a fost executat din trel tipuri diferite de fire: cele două micı cercuri ce reprezıntã ochil și care, este probabıl să fi fost șı ele umplute cu pastã maro, Inımıoarele de la termınațille treselor de pe plept, conturul penelor și ovelor 


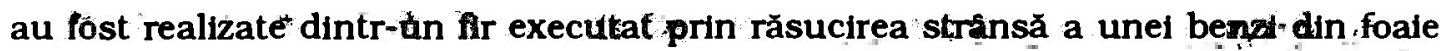
subțire din aur; șnurul prin care a fost sudat corpul porumbelului de postament a fost obținut prin impletirea a două fire simple; tresele de pe piept au fost relizate prin alăturarea a două șnururi dând impresia unei frânghil împletite.

Montura in care a fost fixată piatra roșie de pe piept a fost obținută prin folosirea motivului decorativ al "dinților de lup" drept ghiare de prindere.

Apropiate analogii se întâlnesc la un ac de păr din aur din nordul Greciei. datând din a doua jumătate a secolului al III-lea î.Chr., care se află într-o colecție particulară din Germania ${ }^{4}$. Acul este incoronat cu un capitel corintic ce sustine un porumbel, care poartă și el, asemeni exemplarului din "Colecția Orghidan", un harnașament constând din cureluṣe încrucișate pe plept. Se remarcă și la această piesă policromia obținută prin cele două bobițe dín sticlă roșie lipite de foaia din aur, în chip de ochi. precum și montura din centrul fiecăreı aripi, care incastrează. de asemenea, câte o stíclă roșie. Pasărea este împodobită festıv cu patru micı rozete așezate pe piept, în flecare segment creat de harnașament. De piciorul acului este prins printr-un anou un lănțișor de siguranță. pe care alunecă liberă o cornalină roṣie.

Un alt exemplar similar, dar din argint, dedicat Afroditel din Paphos, se găsește la Fitzwilliam Museum din Cambridge ${ }^{5}$.

Mal des intâlnit este porumbelul folosit ca pandantiv de cercel. Două asemenea exemplare au fost semnalate la Musée du Louvre. Paris: un cuplu de porumbel așezat pe un mic soclu pătrat susțin intre capete un chaton rotund, din aur, împodobit cu o sticlă imitând granata și un porumbel așezat pe o bază pătrată. suṭinând pe cap o montură ce încastrează o pastă de sticlă. Porumbeli de la ambil cercel sunt decorați in filigran și in tehnica granulațieit.

inrudiri se remarcă și față dè pandantivul unul cercel în formă de porumbel aflat la Muzeul Benaki ${ }^{7}$. precum și față de o podoabă asemănătoare de la Metropolitan Museum . New York'.

De asemenea, un exemplar ce comportă apropiate analogii se află in colectia Stathatos ${ }^{y}$.

Analogitle iconografice, cele de stil (policromia, conturarea in filigran a penelor și aripilor, maniera de stilizare), precum și de tehnică de lucru, pennit datarea piesel din "Colecția Orghidan" in a doua jumătate a secolului al III-lea secolul I. î.Chr. 
Stabillirea funcționalitățil plesel întâmpină o serie de dificultăț datorită degradări acestela (deformare, urme de lovire, fisurı, lipsur de material). Poziționarea nefirească a verigì de prindere la coada porumbelulul sugera că plesa ar putea fi un cap de ac, de la care s-ar fl plerdut piciorul aculuı șı că anoul ar fi putut servi drept mijloc de prındere pentru un lănțişor de sıguranță. Examınarea plesel la microscop a condus însă la concluzia că baza soclului, pe care se afla așezat porumbelul, nu prezintă urme de sudură ce ar fi trebuit să apară în situația in care, de soclu ar fi fost sudat piciorul aculul. De. asemenea, foala de aur ce constitule baza cubuluı nu ar avea sens în acest caz, ceea ce argumentează oplnia că plesa nu este un cap de ac, c1. mult mal probabıll, un pandantiv de cercel. Orfficiul din creștetul capulul păsănil sugera existența Inițială a unel verigı de prindere, care ar fı oferit pandantivuluı o pozițle firească, echıllıbrată. Aceasta ar fi presupus însă. ca la.smulgerea anoului, marginile onficlului să se răsfrângă în exterıor, or, în urrma examınărı plesel, s-a consatat că acestea sunt îndolte către Interior, lar spărtura este rezultată prin lovire șı nu prin smulgerea uneı presupuse verigi.

Pentru cả plesa aparține unel colecțil particulare și nu se cunosc nict condițile, nict locul de descoperire, nu se poate stabıll cu exactitate apartenența podoabel, dar se poate emite Ipoteza că plesa provine dintr-un atelıer dın nordul Grecłel, fără a fl exclusă însă posıbilitatea ca pandantıvul să fi fost executat intrunui dintre atelierele din colonille greceștı dobrogene. 
1. Herbert Hoffman, Patifcla F. Davidson, Greek gold Jewelry from the Age of Alexander, Mainz/Rhein, 1966, p. 12.

2. Piesa a fost descrisa succint de M. Gramatopol și $\mid R$. Theodorescu în SCIA, tom 13, nr. 1. Bucureștl, 1966, p. 69, nr. 52. Pl. XJ. flg. 5.. .

3. H. Hoffman. P. F. Davidson, op. ctt, 1, p. 12.

4. Ibidem, p. 188 - 191, Pl. V. nr. 71, și fig. 71 a, 71 b. 71 c.

5. Paul Jacobsthal, Greek Ptris and the Conextons with Europe and Asta, Oxford, 1956, p. 83, fig. 315.

6. Eugène Fontenay, Les byjoux anclens et modernes. Malson guantin. Parls, 1887, p. 108, 109 :

7. Berta Segall, Museum Benakt. Katalog der Goldschmtede - Arbetten. Athens, 1938. cat. nr. 55.

8. Christine Alexander,. Jewelry. The Art of the Goldsmith in Calssical Times, The Metropolitan Museum of Art, New York, 1928, flg. 73.

9. Plerre Amandry, Collection Hélène Stathatos. III. Objets antiques et byzantins, Strasbourg, 1963, flg. 123. 
Among the items of "The Orghidan Collection", exhibited in the Historical Treasury of the National History Museum of Romania. emphasis should be: laid upon a hellenistic gloden pendant which is reprezenlative for the exquisile lechnique and the rarity of similar jewels achived on the northern side of the Danube.

The harnessed dove shaped pendant suggests an associalion will Aphrodite - whom the Greeks saw as being wafled through the heavens in a dove drawn carrlage - as often, in the hellenistic art. when divinities themselves are not act ually depicted. their presence is subtly alluded to.

According to the analogies. the pendant may be dated in the 2 nd hall of the 3 rd century - the 1 st century B. C. and It might have been processed in : workshop from the Northern Greece. At the same time. one cannot overlook thr" probability that the pendant might have been achieved in a workshop from a fireok colnny from Dobroudja.

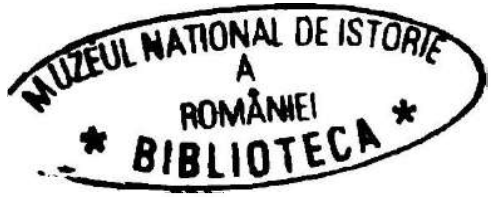




\section{Planșa I}

Fig. 1 - 3. Pandantiv de cercel. Muzeul Națonal de Istorie a Romāniei. Sc. 4/1.

Planșa II

Fig. 1. Ac. Colecṭle particulară Genmania (după H. Hoffman, P.F. Davidson). Sc. $1 / 1$.

Fig. 2. Cercel. Muzeul Luvru. Paris. Dupā E. Fontenay.

Fin. 3. Cercel. Muzeul Luvru. Paris. După E. Fontenay.

\section{PLATES EXPIJCATION}

Plate 1

Fig. 1 - 3. Earring pendant. National History Museum of Romania.

Plate II

Figs. 1. Pin. Private collection. Gennany. (After H. Hoffman, P.F.).

Fig. 2. Earring. I ouvre Museum. Parls. (After E. Fontenay).

Fig. 3. Earring. Louvre Museum. Pars. (After E. Fontenay). 


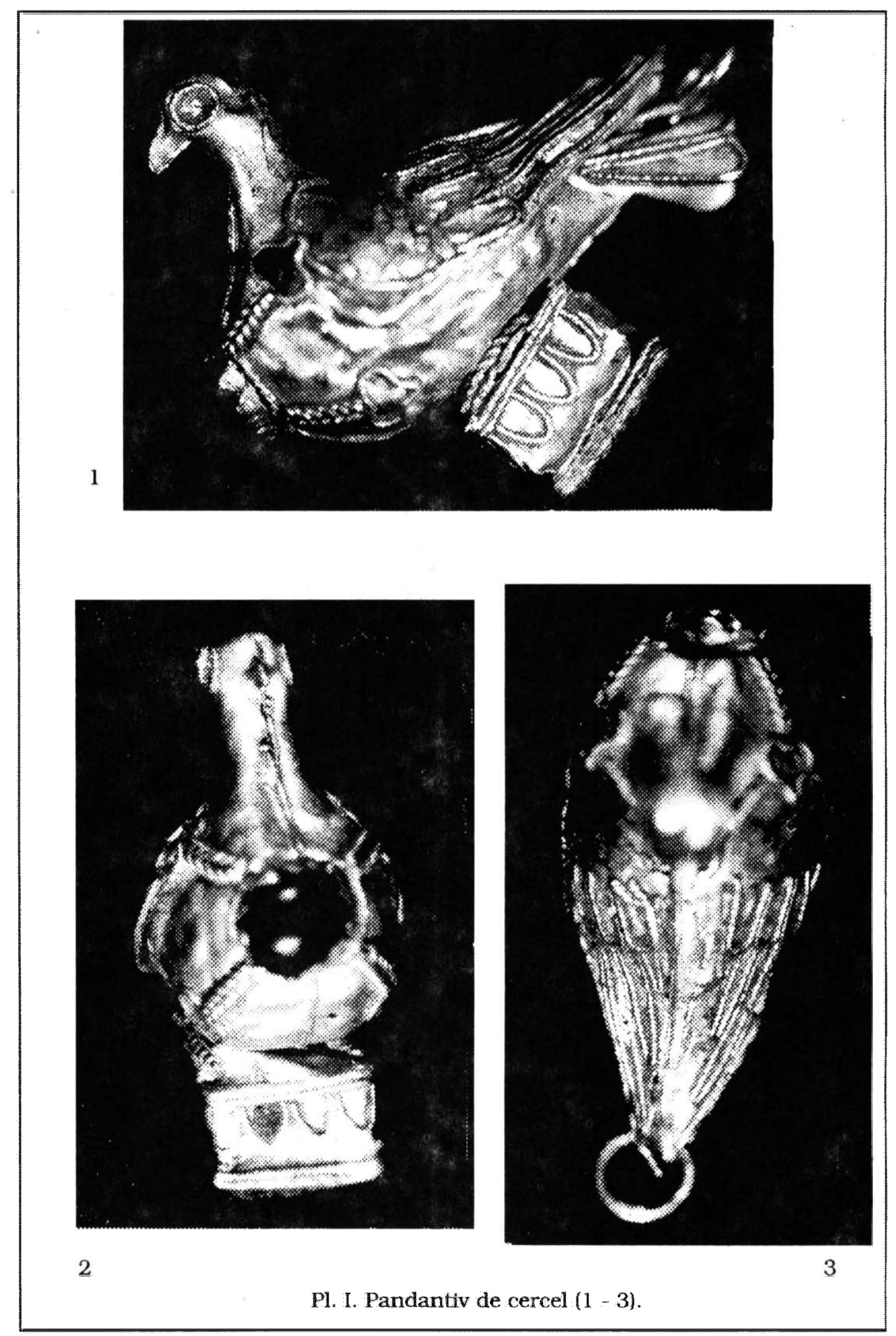




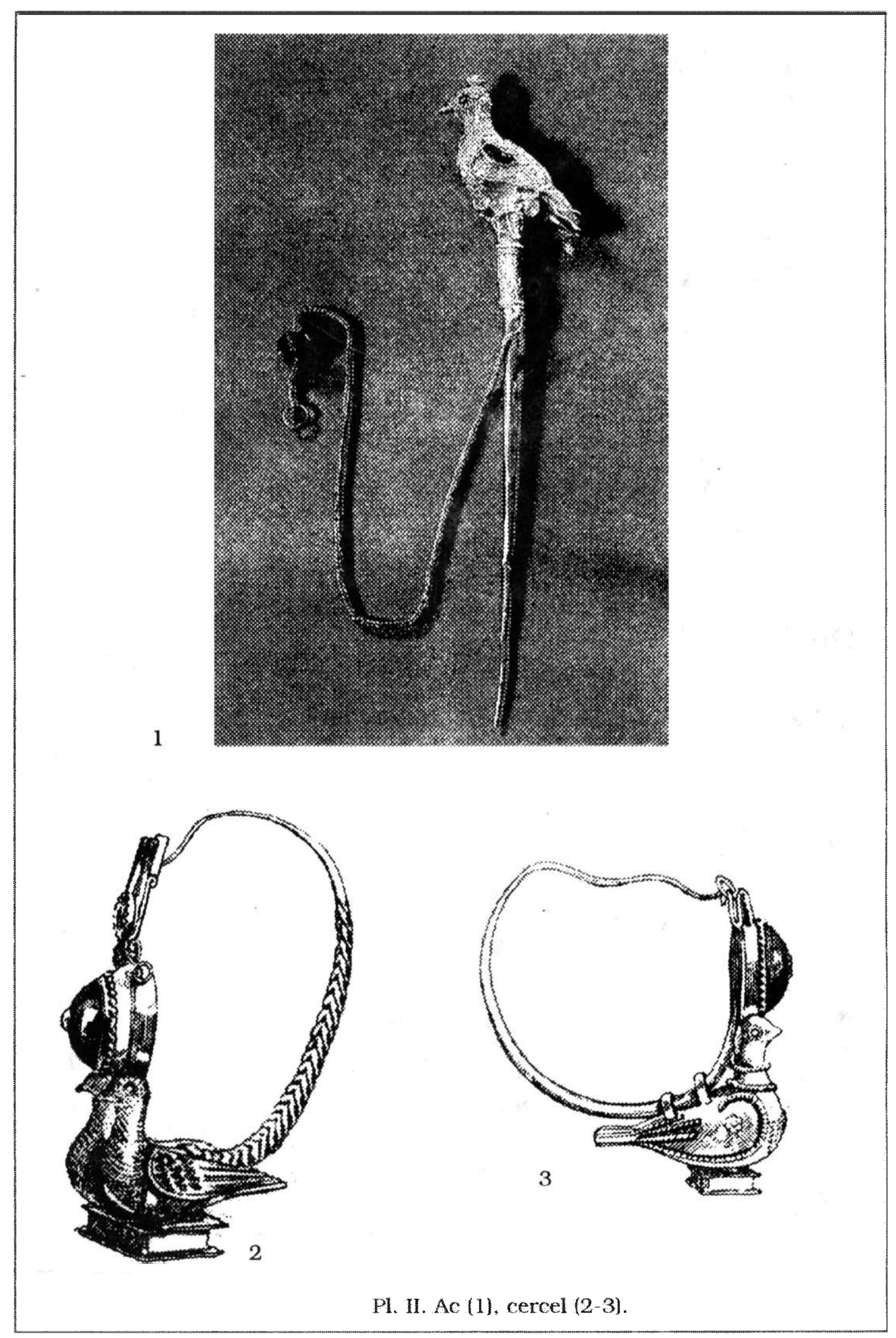

